\title{
A DFT Study on the Efficacy of Linking Agents (Sulfur and Nitrogen) to Connect Trans-azobenzene Sandwiched Between Two Gold Electrodes
}

\author{
C. Karthika, ${ }^{1}$ R. Praveena, ${ }^{2}$ S. Ramachandran, ${ }^{3}$ K. Sadasivam, ${ }^{4, *}$ G. Salgado, ${ }^{5}$ P. Muñoz, ${ }^{6}$ L. Gerli, ${ }^{7}$ L. H. Mendoza-Huizar ${ }^{8, \#}$ \\ 1 Department of Physics, Kongu Engineering College (Autonomous), Perundurai, Erode-638 060, Tamil Nadu, India \\ 2 Department of Chemistry, Bannari Amman Institute of Technology (Autonomous), Sathyamangalam Erode-638 401, Tamil Nadu, India \\ 3 Department of Physics, Arignar Anna College (Arts \& Science), Krishnagiri-635 115, Tamil Nadu, India \\ 4 Department of Physics, Bannari Amman Institute of Technology (Autonomous), Sathyamangalam, Erode-638 401, Tamil Nadu, India \\ 5 Facultad de Ciencias Quimicas, Investigador Extramural,Universidad de Concepcion, Chile \\ ${ }^{6}$ Facultad de Ciencias Exactas, Depàrtamento de Quimica, Universidad Andres Bello, Santiago, Chile \\ 7 Departamento de Quimica Ambiental, Universidad Catolica de la Santisima Concepcion, Concepcion, Chile \\ 8 Autonomous University of Hidalgo State. Academic Area of Chemistry. Carretera Pachuca-Tulancingo Km. 4.5 Mineral de la Reforma, Hgo., México \\ * Corresponding author's e-mail address: dftsada@gmail.com \\ \# Corresponding author's e-mail address: hhuizar@uaeh.edu.mx
}

RECEIVED: September 28, 2020 * REVISED: January 15, 2021 * ACCEPTED: February 2, 2021

\begin{abstract}
Electronic structure calculations were performed to analyze the effectiveness of linking agents (sulfur and nitrogen) in connecting the trans-azobenzene sandwiched between two gold surfaces (Au-atoms). It was analyzed the dynamics of the load carrier and the electronic structure of the molecular backbone by applying an external electric field (EF), also a detailed structural, frontier orbital and natural bond orbital analysis (NBO) were performed. From the NBO analysis, it was possible to predict the path of charge flow in the molecular system. Electrostatic potential mapping allowed us to visualize the charge redistribution in the molecular system caused by the EF application. Our results indicate that when the nitrogen atom is used as a linking agent, the azo group of molecules may enhance their conductivity.
\end{abstract}

Keywords: DFT-field application, Moltronics-linking agent, Molecular orbitals, NBO.

\section{INTRODUCTION}

$\mathbf{M}$ OLTRONICS provides a pathway for the development of the next generation of electronic devices, which are more powerful and compact in comparison to the previous ones. In this sense, the use of a single molecule as an electrical component was first envisioned by Mark Ratner and Aviram in 1974. ${ }^{[1]}$ In late 1990's a lot of research works were conducted to explore the electrical behavior of molecular systems, due to the inability of the existing theories to explain the properties of systems at the molecular level (nano). ${ }^{[2-8]}$ However, even currently, the analysis of the electronic properties at the molecular level implies many complicated issues, by which the theoretical investigations are useful in narrow downing the associated problems. In this kind of molecular electronic systems, the linking agent is the one which facilitates the bond formation between the metal and the organic molecule, because metal-molecule-metal junction is an important factor in determining the conductivity of the molecule. ${ }^{[9,10]}$ Also, the molecular system may be influenced by an external electrical dipolar field (EF) causing changes in the molecular electronic structure in response to it. Generally, organic molecules are the most preferred to be used in moltronic devices due to their extended conjugation $\pi$, for easy electron transfer. ${ }^{[11-13]}$ In this sense, azobenzene exhibits a simple molecular structure and the presence of lone pair of electrons in the azo group $(-\mathrm{N}=\mathrm{N}-)$ facilitates the electron transfer by highly extending the delocalization of $\pi$ electrons. ${ }^{[14]}$ In addition, azo groups have proved to exhibit photo isomerisation which makes them suitable for the fabrication of molecular switches. ${ }^{[15,16]}$ Moreover, 
azobenzene and its derivatives has attracted a lot of interest in various fields like non-linear optics, optical data storage, photochromic materials, dyes etc. Thus, the aim of this theoretical study is to investigate the effectiveness of linking agents (sulfur and nitrogen) in connecting the molecule (azobenzene) with the electrode (Au-atom). Since, the effectiveness of these linking agents is an important part in the design of new molecular wires and electronic devices. ${ }^{[17-19]}$. During the present study the azobenzene is kept in its trans-conformation, which has a better conductance, ${ }^{[20]}$ and a major thermodynamical stability in comparison to the cis-conformation. ${ }^{[21]}$

\section{COMPUTATIONAL DETAILS}

All the calculations were performed at the DFT/B3LYP level of theory, ${ }^{[22,23]}$ as implemented in Gaussian 09W software package. ${ }^{[24]}$ Also, $\mathrm{Au}$ atoms were described through the LANL2DZ basis set, ${ }^{[25-27]}$ in order to minimize the computational cost with the usage of effective core potential to perform valence electron calculations. To compare the effectiveness of the commonly used linking agent sulfur (S) with the nitrogen $(\mathrm{N})$, the terminals of the optimized structure of trans-azobenzene is bonded to $-\mathrm{SH}$ group and $-\mathrm{NH}_{2}$ groups yielding thiolated azobenzene $(\mathrm{M}-\mathrm{I})$ and azodianiline (M-II) respectively, then these structures were fully reoptimized. Also, it is important to mention that $\mathrm{Au}$ can couple covalently with $\mathrm{M}-\mathrm{I}$ and $\mathrm{M}-\mathrm{II}$ through $\mathrm{S}$ and $\mathrm{N}$ respectively by replacing $\mathrm{H}$-atom. ${ }^{[17]}$ Hence the $\mathrm{H}$-atoms in $-\mathrm{SH}$ and $-\mathrm{NH}_{2}$ groups were replaced by gold atoms to represent the metal electrode, ${ }^{[28]}$ and named as extended molecule-I (EM-I) and extended molecule-II (EM-II) respectively for further calculations. In EM-II, since $\mathrm{N}$-atom is used as a linking agent two $\mathrm{Au}$-atoms per $\mathrm{N}$-atom are bonded to build it a chemical stable structure.

Here, it is important to comment that in the nanoscale regime, the contact (bond) made between the metal electrode and the molecule may alter the electronic structure of the last one. ${ }^{[7]}$ Thus, in order to predict such effects $\mathrm{Au}$ atoms were connected to the molecule through the linking agent. Also, the EF was applied along the molecular axis of EM-I and EM-II, with the field strength varying from 0 to $0.26 \mathrm{~V} / \AA$ in five steps as implemented in Gaussian 09W suite of program. Also, to reveal the existence of inter molecular interactions Natural Bond Orbital (NBO) calculations were carried out using NBO 3.1 program. ${ }^{[29]}$ The molecular orbitals (MOs) and the electrostatic potential (ESP) mappings were plotted using GView05 program. ${ }^{[30]}$ The density of states (DOS) was calculated employing GaussSum program. ${ }^{[31]}$ The molecular descriptors such as hardness $(\eta)$ and softness $(S)$ were calculated through the equations (1) and (2), respectively, ${ }^{[32]}$

$$
\begin{aligned}
& \text { Hardness: } \eta=\frac{\left(E_{\mathrm{LUMO}}-E_{\text {Hомо }}\right)}{2} \\
& \text { Softness: } S=\frac{1}{2 \eta}
\end{aligned}
$$

The values of these descriptors allow predicting the ease with which an electron may be transferred through the metal-molecular system.

\section{RESULTS AND DISCUSSION}

\section{Structural Analysis}

The conductivity of a molecule is expected to be high when it is in a planar configuration. ${ }^{[33]}$ Hence, the trans-conformation of azobenzene was used for the entire study. The structure of the molecules was analyzed in order to find out the influence of the linking agents and Au atoms over the planarity of the molecule. The bond lengths of the optimized structures are reported in Table 1 , and the atom numbering of the studied molecules are depicted in Figure 1.

The bond length of $\mathrm{C} 2-\mathrm{C} 3, \mathrm{C} 3-\mathrm{C} 4, \mathrm{C}-\mathrm{N}$ and $\mathrm{N}=\mathrm{N}$ bonds in azobenzene are $1.402 \AA, 1.417 \AA, 1.433 \AA$ and $1.290 \AA$ \& respectively, which are in close agreement with the values reported in the literature. ${ }^{[34,35]}$ The inclusion of linking agents (sulfur and nitrogen atoms) and $\mathrm{Au}$ atoms slightly alter the bond lengths. Note that the parallel bonds to the molecular axis ( $\mathrm{C} 2-\mathrm{C} 3, \mathrm{C} 5-\mathrm{C} 6$ and $\mathrm{C} 4-\mathrm{N} 7)$ are shortened and the other bonds are elongated. The bond lengths variations are higher in EM-II in comparison to EMI. The $\mathrm{N}=\mathrm{N}$ bond length increases to 1.292 and $1.305 \AA$ in EM-I and EM-II, respectively. On the other hand, the C-N bond length is shortened to 1.428 and $1.410 \AA$ in $\mathrm{EM}-\mathrm{I}$ and EM-II, respectively. The S-C and N-C bond length is elongated with the inclusion of $\mathrm{Au}$ atoms. The $\mathrm{Au}-\mathrm{S}$ and $\mathrm{Au}-\mathrm{N}$ bond lengths are 2.398 and $2.064 \AA$, respectively.

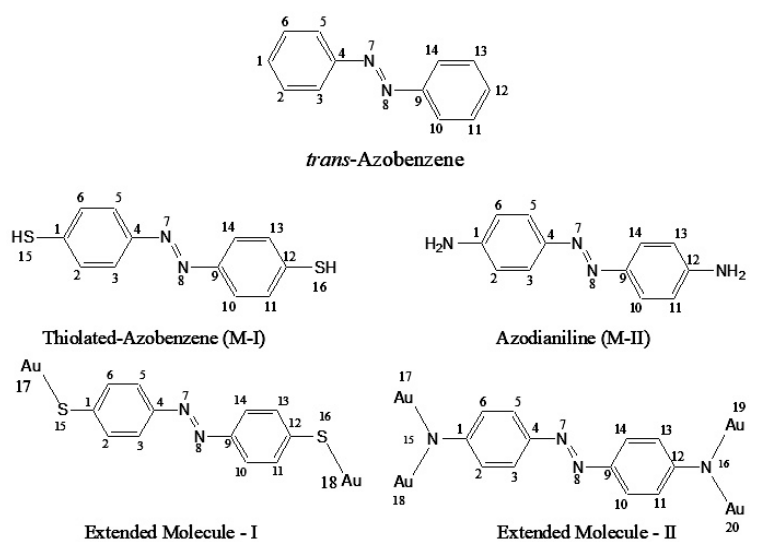

Figure 1. Structure and atom numbering of the set of molecules. 
Table 1. Bond lengths optimized at the B3LYP/LANL2DZ level of theory.

\begin{tabular}{cccccc}
\hline \multirow{2}{*}{ Bond } & \multicolumn{5}{c}{ Bond length / } \\
\cline { 2 - 6 } & Azobenzene & M-I & EM-I & M-II & EM-II \\
\hline C1-C2 & 1.413 & 1.415 & 1.417 & 1.424 & 1.436 \\
C2-C3 & 1.402 & 1.398 & 1.399 & 1.395 & 1.389 \\
C3-C4 & 1.417 & 1.418 & 1.419 & 1.420 & 1.425 \\
C4-C5 & 1.412 & 1.411 & 1.413 & 1.414 & 1.419 \\
C5-C6 & 1.406 & 1.403 & 1.403 & 1.399 & 1.392 \\
C6-C1 & 1.409 & 1.409 & 1.412 & 1.420 & 1.432 \\
C4-N7 & 1.433 & 1.427 & 1.428 & 1.421 & 1.410 \\
N7-N8 & 1.290 & 1.293 & 1.292 & 1.297 & 1.305 \\
C-H (Average) & 1.087 & 1.086 & 1.086 & 1.087 & 1.086 \\
S-C & - & 1.838 & 1.840 & - & - \\
S-Au & - & - & 2.398 & - & - \\
N-C (Terminal atom) & - & - & - & 1.392 & 1.403 \\
N-Au & - & - & - & - & 2.064 \\
\hline
\end{tabular}

When the EF is applied on EM-I, slight changes of the order $\sim 0.01 \AA$ are observed only in the left side ring whereas the right side ring structure is not affected, it is probably because the atoms in the left end experiences stronger field compared to the right end due to the direction of the electric field. Same changes were observed on the right side ring with the reversal of field direction. In EM-I, C4-C7 and C1-S15 bond length is shortened from 1.428 to $1.402 \AA$ and 1.840 to $1.811 \AA$ A respectively and the $7 \mathrm{~N}=8 \mathrm{~N}$ is slightly elongated to $1.306 \AA$ due to the external EF. The same trend is observed in EM-II with a slightly higher magnitude. These variations in bond length occur in order to balance the conjugation in the molecule. In EM-I and EM-II Au atoms are located out of the molecular axis due to steric effect between the lone pair of electron in $\mathrm{N}$ or $\mathrm{S}$ and $\mathrm{Au}$ atom. When EF is applied, electrons (lone pair electrons) get drifted towards right side of the molecule. Therefore, Au atoms in the left terminal of EM-I and EM-II start to align gradually along the molecular axis as the EF strength increases. This is evidenced by the increase in the bond angle $1 \mathrm{C}-15 \mathrm{~S}-17 \mathrm{Au}$ from $103^{\circ}$ to $107^{\circ}$ in EM-II and $1 \mathrm{C}-15 \mathrm{~N}-17 \mathrm{Au} / 1 \mathrm{C}-15 \mathrm{~N}-18 \mathrm{Au}$ from $118^{\circ}$ to $124^{\circ}$ in EM-II. At the same time, the $\mathrm{Au}$ atoms in the right terminal remain unaffected, due to the field direction. Overall, the molecule retains its planarity even after the application of EF and noticeable changes occurs only near of the Au (metal) atom, due to the weak bonding between metal and molecule. Also, it is possible to note that there is not twisting over the $\mathrm{N}=\mathrm{N}$, which might lead to the transformation between cis and trans conformation. ${ }^{[36]}$

\section{Molecular Orbital Analysis}

Being the boundary line for the electrons in the molecule, the frontier orbitals (Highest occupied molecular orbitalHOMO and Lowest unoccupied molecular orbital-LUMO) are the central factor in determining the electrical properties of a molecule. ${ }^{[37]}$ However, the molecular orbitals close to the frontier orbitals are influenced by the applied EF, by which they were analyzed, too.

Figure 2 depicts the spatial distribution of the MOs of the azobenzene, M-I, M-II, EM-I and EM-II, where the red and green color regions indicate different phases of the MOs. The completely delocalized LUMO in plain azobenzene suggests that the conductance is dominated by an electron transfer rather than hole transfer (due to localized HOMO). But the bonding of the linking agents ( $\mathrm{S} / \mathrm{N}$ atoms) to azobenzene in $\mathrm{M}-\mathrm{I}$ and $\mathrm{M}-\mathrm{II}$ interchanges HOMO and HOMO-I position. This is due to the formation of a new HOMO orbital (completely delocalized) by the hybridization between $\mathrm{p}_{z}$ orbitals of carbon atoms and linking agent, which in turn decreases the HOMO-LUMO gap (HLG) from $3.654 \mathrm{eV}$ to $3.354 \mathrm{eV}$ and $3.225 \mathrm{eV}$ in $\mathrm{M}-\mathrm{I}$ and $\mathrm{M}-\mathrm{II}$, respectively. Also note that LUMO is not affected by the addition of the linking agent, but the addition of linking agents not only improves the metal-molecule contact but also enhances the conductivity of the molecule (both electron and hole transfer)

The bonding of linking agents with $\mathrm{Au}$ atoms is causing the formation of new energy levels above the $\mathrm{HOMO}$, thereby shifts the original LUMO to the next energy level leading to the reduction in HLG from 3.354 to 2.552 $\mathrm{eV}$ and 3.225 to $1.361 \mathrm{eV}$ in EM-I and EM-II, see Table 2. Also, observe that HOMO remains same in both the cases, see Figure 2. In EM-II the HOMO-1 and HOMO-2 get interchanged after the bonding with $\mathrm{Au}$ atoms. As a result, in addition to frontier orbitals the HOMO-1 and LUMO+1 orbitals are also delocalized throughout EM-II. The resistance of the molecule is expected to be low if the Fermi level $(\mathrm{FL})$ of the electrode is in alignment with any one of the frontier orbital energy levels. ${ }^{[11]}$ Interestingly, in the EM-II the reported value $(-5.31 \mathrm{eV})$ of the FL for the bulk gold electrode ${ }^{[38]}$ is in exact alignment with the HOMO energy level $(-5.33 \mathrm{eV})$, which may be observed from the density of states plot depicted in Figure 3.

In Figures 4 and 5 is depicted the evolution of energy levels and the spatial distribution of HOMO and LUMO with the application of the EF. In EM-I, HOMO and LUMO are slightly delocalized at right terminal atoms due to the EF. As the EF intensity increases, the gradual shift in $\mathrm{HOMO}$ and LUMO toward the FL of the bulk gold enhances the charge migration (both electron and hole) with the decrease the HLG from 2.552 to $1.064 \mathrm{eV}$. On the other hand, the HOMOand LUMO+ levels shift away from each other. This means the limited flow of charges through HOMO- and LUMO+ 


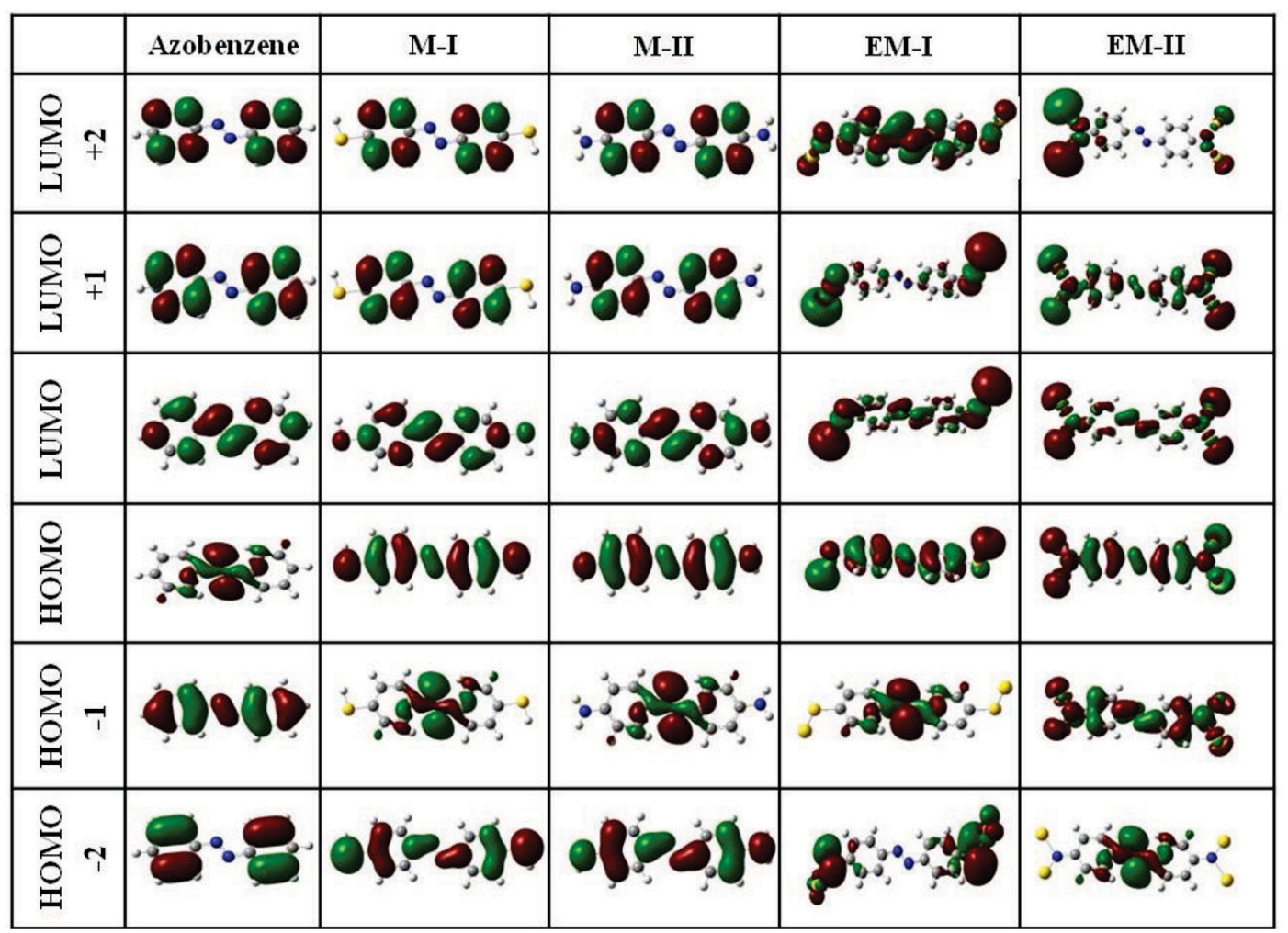

Figure 2. Some image (single column width: 215 points).

Table 2. Influence of the electric field on the HOMO-LUMO gap values for EM-I and EM-II.

\begin{tabular}{cccccc}
\hline $\begin{array}{c}\text { Electric field / } \\
\vee \AA^{-1}\end{array}$ & $\begin{array}{c}\text { Azobenzene / } \\
\mathrm{eV}\end{array}$ & $\begin{array}{c}\mathrm{M}-\mathrm{I} / \\
\mathrm{eV}\end{array}$ & $\begin{array}{c}\mathrm{M}-\mathrm{II} / \\
\mathrm{eV}\end{array}$ & $\begin{array}{c}\mathrm{EM}-\mathrm{I} / \\
\mathrm{eV}\end{array}$ & $\begin{array}{c}\mathrm{EM}-\mathrm{II} / \\
\mathrm{eV}\end{array}$ \\
\hline 0 & 3.654 & 3.354 & 3.225 & 2.552 & 1.361 \\
0.05 & - & - & - & 2.334 & 1.328 \\
0.10 & - & - & - & 1.932 & 1.246 \\
0.15 & - & - & - & 1.525 & 1.177 \\
0.21 & - & - & - & 1.204 & 1.149 \\
0.26 & - & - & - & 1.064 & 1.206 \\
\hline
\end{tabular}

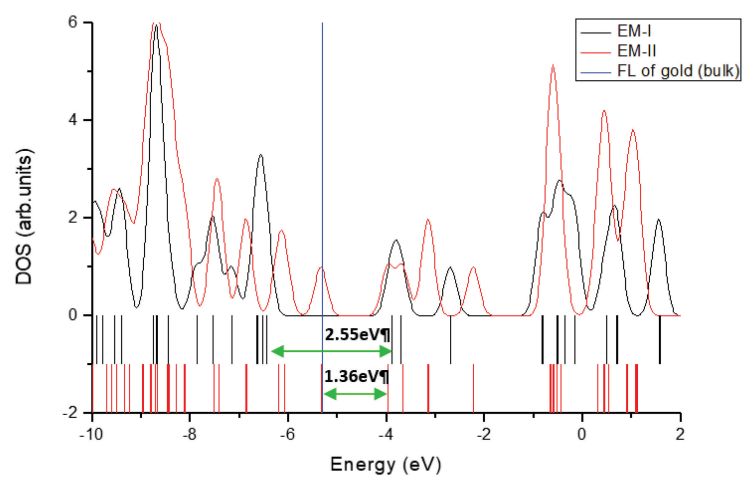

Figure 3. Plot of density of states of EM -I and EM-II. orbitals. In EM-I, the field has an equal influence on HOMO and LUMO, where as in EM-II only the HOMO level shifts above FL of gold with a slight decrease in HLG from 1.361 to $1.206 \mathrm{eV}$. Thus, in EM-II, the hole transfer plays a significant role. The other energy levels and its spatial distributions of MOs remain almost unaffected during the application of the electric field. Notably, EM-II has closely distributed LUMO levels, in comparison to EM-I, indicating large charge flow even though the HLG reduction is less.

\section{Natural Bond Orbital Analysis}

NBO analysis is one of the successful tools to predict the conjugative interaction i.e. the charge transfer in a molecular system. ${ }^{[39]}$ The change in the stabilization energy during the application of the electric field, gives an indication about the path for the electron transfer. All the stabilization energy values are reported in the Tables 3 and 4. When, the electric field strength is increased gradually from 0 to $0.15 \mathrm{~V} / \AA$ in $\mathrm{EM}-\mathrm{I}$ and $\mathrm{EM}-\mathrm{Il}$ the stabilization energy between the bonds $\pi(\mathrm{C} 1-\mathrm{C} 6) \& \pi^{*}(\mathrm{C} 4-\mathrm{C} 5), \pi(\mathrm{C} 4-\mathrm{C} 5)$ \& $\pi^{*}(\mathrm{~N} 7-\mathrm{N} 8)$ and $\pi(\mathrm{C} 9-\mathrm{C} 10)$ \& $\pi^{*}(\mathrm{C} 11-\mathrm{C} 12)$ increases slowly. On the other hand, the stabilization energy decreases between the bonds $\pi\left(\right.$ C11-C12) \& $\pi^{*}$ (C9-C10), $\pi(\mathrm{C} 9-\mathrm{C} 10) \& \pi^{*}$ (N7-N8), $\pi(\mathrm{C} 4-\mathrm{C} 5) \& \pi^{*}(\mathrm{C} 1-\mathrm{C} 6)$. Thus, it is clear that the electron interaction between the bonds $\mathrm{C} 1$ $\mathrm{C} 6, \mathrm{C} 4-\mathrm{C} 5, \mathrm{~N} 7-\mathrm{N} 8, \mathrm{C} 9-\mathrm{C} 10$ and $\mathrm{C} 11-\mathrm{C} 12$ towards the right direction has been enhanced by suppressing the interaction 


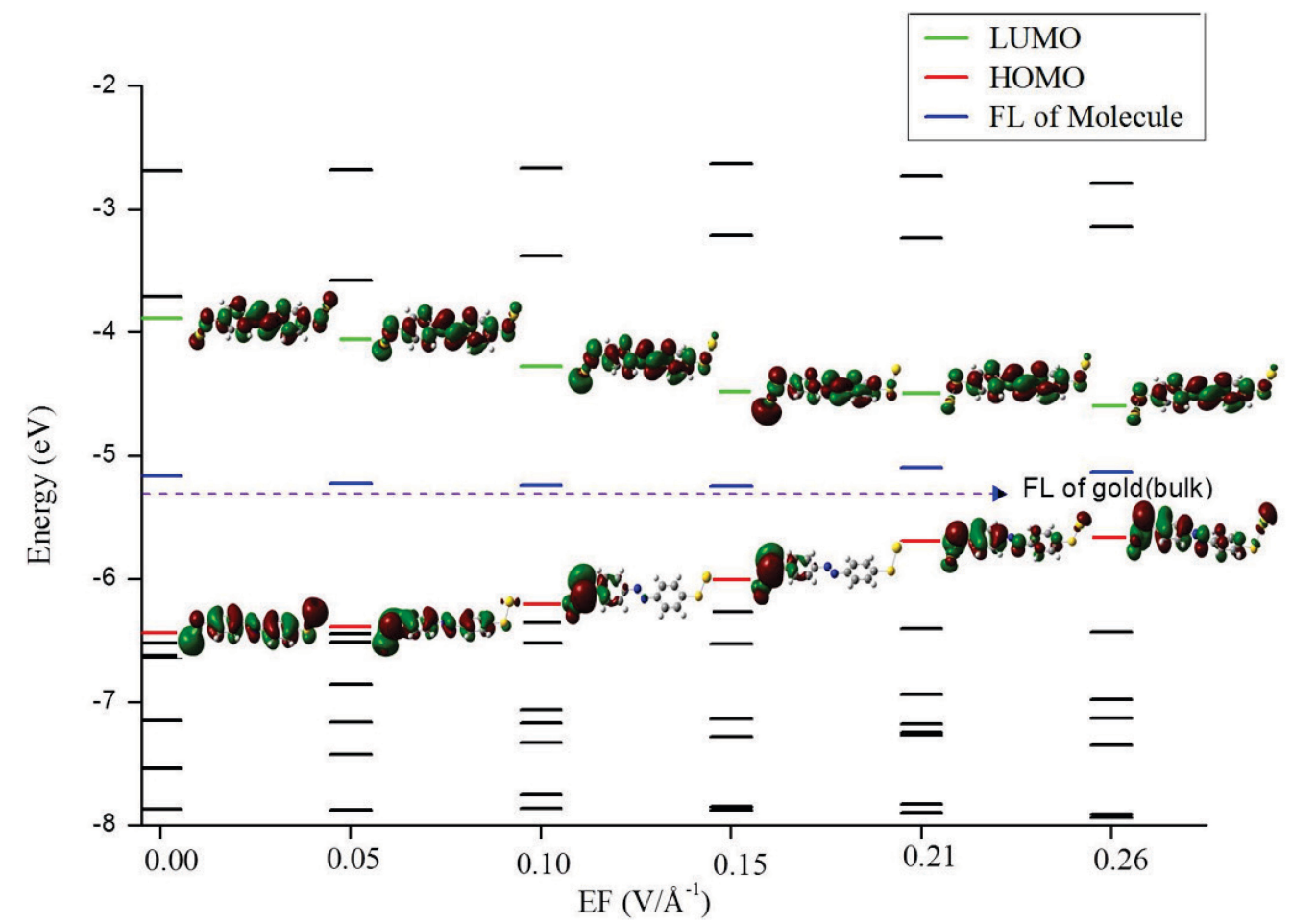

Figure 4. Energy distribution in EM-I with HOMO \& LUMO Isosurface for various EF strength.

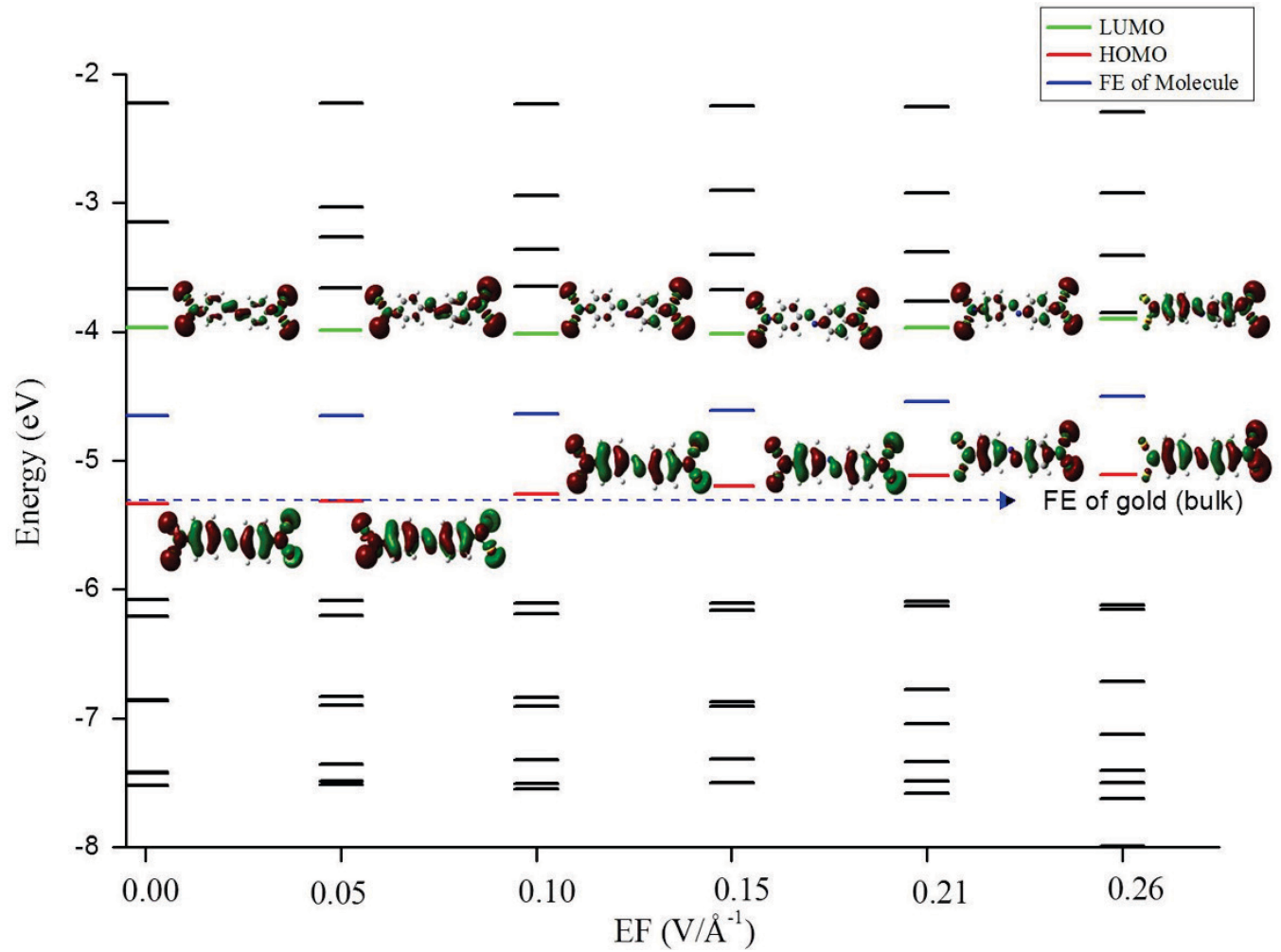

Figure 5. Energy distributions in EM-II with HOMO and LUMO Isosurface for various EF strength. 
Table 3. Second order perturbation theory analysis of Fock matrix for NBO analysis for EM-I

\begin{tabular}{|c|c|c|c|c|c|c|c|}
\hline \multirow{2}{*}{ Donor(i) } & \multirow{2}{*}{ Acceptor(j) } & \multicolumn{6}{|c|}{ Stabilization energy of EM-I / $\mathrm{kcal} \mathrm{mol}^{-1}$} \\
\hline & & $E F=0.00 \mathrm{~V} / \AA$ & $E F=0.05 \mathrm{~V} / \AA$ & $E F=0.10 \mathrm{~V} / \AA$ & $E F=0.15 \mathrm{~V} / \AA$ & $E F=0.21 \mathrm{~V} / \AA$ & $E F=0.26 \mathrm{~V} / \AA$ \\
\hline \multirow[t]{2}{*}{$\pi(C 9-C 10)$} & $\pi^{*}(\mathrm{~N} 7-\mathrm{N} 8)$ & 23.13 & 22.12 & 21.32 & 20.72 & 20.88 & 21.14 \\
\hline & $\pi^{*}(\mathrm{C} 11-\mathrm{C} 12)$ & 22.87 & 23.53 & 24.23 & 24.96 & 26.14 & 26.78 \\
\hline \multirow[t]{2}{*}{$\pi(\mathrm{C} 4-\mathrm{C} 5)$} & $\pi^{*}(\mathrm{~N} 7-\mathrm{N} 8)$ & 23.13 & 24.22 & 25.52 & 26.99 & 3.71 & 3.88 \\
\hline & $\pi^{*}(\mathrm{C} 1-\mathrm{C} 6)$ & 22.91 & 22.27 & 21.70 & 21.18 & - & - \\
\hline$\pi(\mathrm{C} 11-\mathrm{C} 12)$ & $\pi^{*}(\mathrm{C} 9-\mathrm{C} 10)$ & 20.46 & 19.89 & 19.45 & 19.08 & 18.78 & 18.76 \\
\hline$\pi(\mathrm{C} 1-\mathrm{C} 6)$ & $\pi^{*}(\mathrm{C} 5-\mathrm{C} 4)$ & 20.42 & 20.93 & 21.52 & 22.18 & - & - \\
\hline \multirow[t]{3}{*}{$\mathrm{LP}(1) \mathrm{C} 4$} & $\pi^{*}(\mathrm{~N} 7-\mathrm{N} 8)$ & - & - & - & - & 120.19 & 129.67 \\
\hline & $\pi^{*}(\mathrm{C} 5-\mathrm{C} 6)$ & - & - & - & - & 60.25 & 58.07 \\
\hline & $\pi^{*}(\mathrm{C} 2-\mathrm{C} 3)$ & - & - & - & - & 58.64 & 57.22 \\
\hline$\pi(\mathrm{C} 5-\mathrm{C6})$ & $\mathrm{LP}^{*}(1) \mathrm{C} 1$ & - & - & - & - & 58.43 & 57.68 \\
\hline$\pi(C 2-C 3)$ & $\mathrm{LP}^{*}(1) \mathrm{C} 1$ & - & - & - & - & 55.28 & 55.05 \\
\hline LP(2) S15 & $\mathrm{LP}^{*}(1) \mathrm{C} 1$ & - & - & - & - & 42.23 & 50.74 \\
\hline
\end{tabular}

Table 4. Second order perturbation theory analysis of Fock matrix for NBO analysis for EM-II

\begin{tabular}{|c|c|c|c|c|c|c|c|}
\hline \multirow{2}{*}{ Donor(i) } & \multirow{2}{*}{ Acceptor(j) } & \multicolumn{6}{|c|}{ Stabilization energy of EM-II / $\mathrm{kcal} \mathrm{mol}^{-1}$} \\
\hline & & $E F=0.00 \mathrm{~V} / \AA$ & $E F=0.05 \mathrm{~V} / \AA$ & $\mathrm{EF}=0.10 \mathrm{~V} / \AA$ & $E F=0.15 \mathrm{~V} / \AA$ & $E F=0.21 \mathrm{~V} / \AA$ & $E F=0.26 \mathrm{~V} / \AA$ \\
\hline \multirow[t]{2}{*}{$\pi(\mathrm{C} 9-\mathrm{C} 10)$} & $\pi^{*}(\mathrm{~N} 7-\mathrm{N} 8)$ & 26.55 & 25.21 & 24.74 & 24.91 & 25.56 & - \\
\hline & $\pi^{*}(\mathrm{C} 11-\mathrm{C} 12)$ & 21.88 & 22.72 & 23.56 & 24.43 & 25.36 & - \\
\hline \multirow{2}{*}{$\pi(C 4-C 5)$} & $\pi^{*}(\mathrm{~N} 7-\mathrm{N} 8)$ & 26.38 & 28.23 & 30.57 & - & 36.65 & - \\
\hline & $\pi^{*}(\mathrm{C} 1-\mathrm{C} 6)$ & 22.03 & 21.18 & 20.68 & - & 20.09 & - \\
\hline$\pi(\mathrm{C} 11-\mathrm{C} 12)$ & $\pi^{*}(\mathrm{C} 9-\mathrm{C} 10)$ & 25.14 & 24.14 & 23.61 & 23.35 & 23.3 & - \\
\hline$\pi(\mathrm{C} 1-\mathrm{C} 6)$ & $\pi^{*}(\mathrm{C} 4-\mathrm{C} 5)$ & 24.99 & 26.04 & 27.32 & - & 30.72 & - \\
\hline$\sigma(\mathrm{N} 15$-Au18) & $\pi^{*}(\mathrm{C} 1-\mathrm{N} 15)$ & - & - & - & 160.3 & - & - \\
\hline$\sigma(\mathrm{N} 15$-Au17) & $\pi^{*}(\mathrm{C} 1-\mathrm{N} 15)$ & - & - & - & 151.63 & - & - \\
\hline \multirow[t]{2}{*}{$\sigma(\mathrm{N} 16$-Au19) } & $\pi^{*}(\mathrm{C} 12-\mathrm{N} 16)$ & - & - & - & - & - & 150.27 \\
\hline & $\sigma^{*}($ N16 -Au20) & - & - & - & - & - & 166.4 \\
\hline \multirow[t]{2}{*}{ LP(1) C4 } & $\pi^{*}(\mathrm{~N} 7-\mathrm{N} 8)$ & - & - & - & - & - & 170.47 \\
\hline & $\pi^{*}(\mathrm{C} 12-\mathrm{N} 16)$ & - & - & - & - & - & 143.39 \\
\hline$\sigma(\mathrm{N} 16$-Au20) & $\sigma^{*}($ N16 -Au19) & - & - & - & - & - & 162.94 \\
\hline \multirow[t]{2}{*}{$\pi(\mathrm{C} 12-\mathrm{N} 16)$} & $\sigma^{*}(\mathrm{~N} 16-\mathrm{Au20})$ & - & - & - & - & - & 113.07 \\
\hline & $\sigma^{*}(\mathrm{~N} 16-A u 19)$ & - & - & - & - & - & 103.38 \\
\hline
\end{tabular}

toward left direction. These variations give a clear picture about the electron flow, i.e. the five bonds provide the pathway for the electron flow.

In the case of EM-I, when the values of the electric field increases above $0.15 \mathrm{~V} / \AA$, suddenly some of the older interactions vanish. At the same time, the interactions involving LP (1) C4 and LP* (1) C1 participate with different stabilization energies (120.19 kcal / mol, $60.25 \mathrm{kcal} / \mathrm{mol}$, etc.). This is because, when EM-I experiences a strong EF, most of the electrons are drifted away leading to instability in the left ring ( $\mathrm{C} 1$ to $\mathrm{C} 6$ ). When $0.15 \mathrm{~V} / \AA \mathrm{EF}$ is applied to
EM-Il a high stabilization energy (160.3 kcal / mol, 151.63 $\mathrm{kcal} / \mathrm{mol}$ ) is observed between the linking agent N15 and $\mathrm{Au}$ atoms on the left terminal. Furthermore, during the application of high field strength as $0.26 \mathrm{~V} / \AA$, all the older interactions disappear, and new interactions throughout the EM-II are observed, especially around the terminal N, $\mathrm{Au}$ atoms and LP (1) C4 and LP (1) C9 orbitals. This is attributed to the strong EF, which completely swept away the electrons. Notably, in EM-II Au atoms are also involved in the interaction where as in EM-I no significant interactions involving $\mathrm{Au}$ atoms are observed. 


\section{Electrostatic Potential and Dipole Moment}

In general, symmetric molecules like trans-azobenzene will exhibit zero dipole moment. But the application of an EF causes polarization and can be observed by considering the value of the moment magnitude of the dipole. The net dipole moment is boosted up to 17.02 Debye and 33.304 Debye along the molecular axis in EM-I and EM-II, respectively, when an EF of $0.26 \mathrm{~V} / \AA$ is applied. Thus, considering that the ESP arises due to the opposing contributions between nuclei and electrons, ${ }^{[40]}$ in Figure 6 the red region is related to more negative electrostatic potential and the blue region to more positive electrostatic potential. From ESP plots is possible to observe the accumulation of more negative charges close to the right terminal, at the same instance left side of the molecule becomes more positive, and it is clear that the charge accumulation is higher in EMII in comparison to EM-I, see Figure 6.

\section{Hardness and Softness}

The global hardness is a descriptor, which is directly related to the molecular stability and similarly the global softness is proportional to the reactivity of the molecular system. ${ }^{[41]}$ Hence, it is expected to have an easy flow of electron through the molecule, when the softness value is high. The
Table 5. Molecular descriptors for azobenzene, $\mathrm{M}-\mathrm{I}$ and $\mathrm{M}-\mathrm{II}$

\begin{tabular}{cccc}
\hline Molecule & Hardness (eV) & Softness (eV) & $\begin{array}{c}\text { Dipole moment } \\
\text { (Debye) }\end{array}$ \\
\hline Azobenzene & 1.827 & 0.274 & 0.000 \\
M-I & 1.677 & 0.298 & 0.000 \\
M-II & 1.612 & 0.310 & 0.000 \\
\hline
\end{tabular}

magnitude of the dipolar moment, $\eta$ and $S$ were calculated using the frontier orbital energies and their values are reported in Table 5 for azobenezene, M1 and M2, while the same descriptors for EM-I and EM-II are reported in Table 6. Note that the hardness value of EM-II is low $(0.681 \mathrm{eV})$, while that its softness value $\left(0.735 \mathrm{eV}^{-1}\right)$ and this is higher in comparison to the obtained for EM-I. When the electrical field is applied the softness of the EM-I and EM-II are increased to $0.940 \mathrm{eV}^{-1}$ and $0.829 \mathrm{eV}^{-1}$, respectively. Last result indicates an increment in the reactivity (charge transfer) of the EM-I and EM-II in response to the EF. In all cases observe that the dipolar moment is increased as the $\mathrm{EF}$ is augmented.

Here, it is convenient to mention that, a single gold atom can be considered a raw model of a gold electrode.

Table 6. Molecular descriptors for EM-I and EM-II under the influence of the different values of the electric field

\begin{tabular}{|c|c|c|c|c|c|c|}
\hline \multirow{2}{*}{$\begin{array}{l}\text { Electric Field } \\
(\mathrm{V} / \AA)\end{array}$} & \multicolumn{3}{|c|}{ EM-I } & \multicolumn{3}{|c|}{ EM-II } \\
\hline & Hardness (eV) & Softness (eV) & $\begin{array}{c}\text { Dipole moment } \\
\text { (Debye) }\end{array}$ & Hardness (eV) & Softness (eV) & $\begin{array}{c}\text { Dipole moment } \\
\text { (Debye) }\end{array}$ \\
\hline 0 & 1.276 & 0.392 & 0.000 & 0.681 & 0.735 & 0.000 \\
\hline 0.05 & 1.167 & 0.428 & 2.116 & 0.664 & 0.753 & 5.416 \\
\hline 0.10 & 0.966 & 0.518 & 4.307 & 0.623 & 0.803 & 11.279 \\
\hline 0.15 & 0.763 & 0.656 & 6.678 & 0.588 & 0.850 & 18.073 \\
\hline 0.21 & 0.602 & 0.831 & 12.829 & 0.575 & 0.870 & 26.158 \\
\hline 0.26 & 0.532 & 0.940 & 17.024 & 0.603 & 0.829 & 33.304 \\
\hline
\end{tabular}

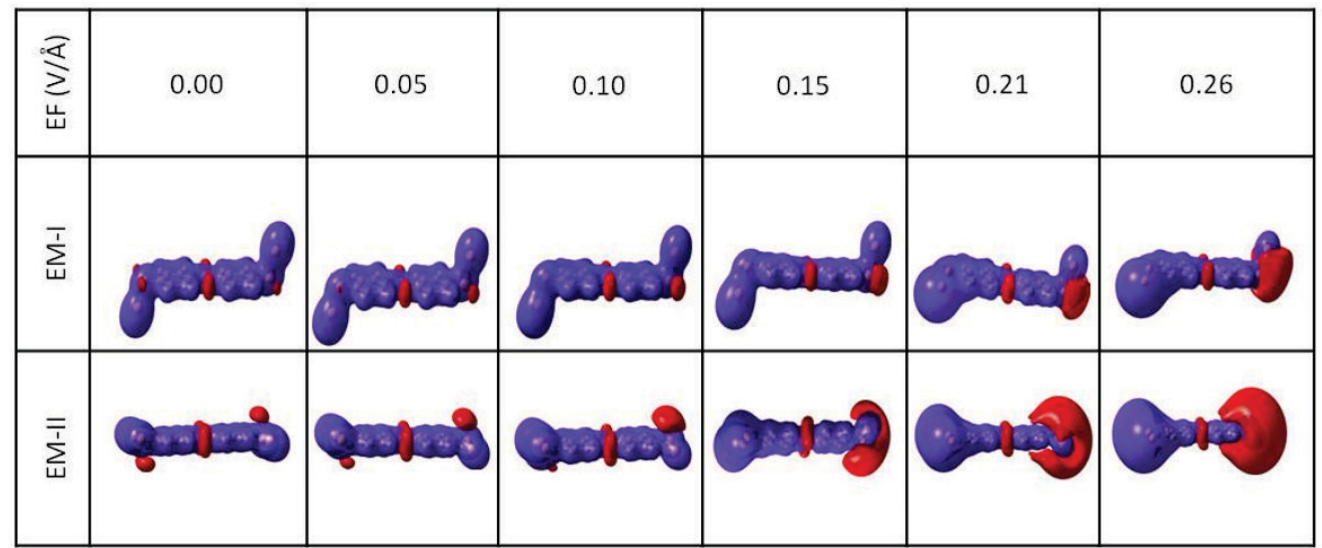

Figure 6. Molecular Electrostatic Potential of EM-I \& EM-II for various applied EF showing the electropositive and electronegative regions (Isovalue 0.035 e u. $\mathrm{a}^{-3}$ ). 


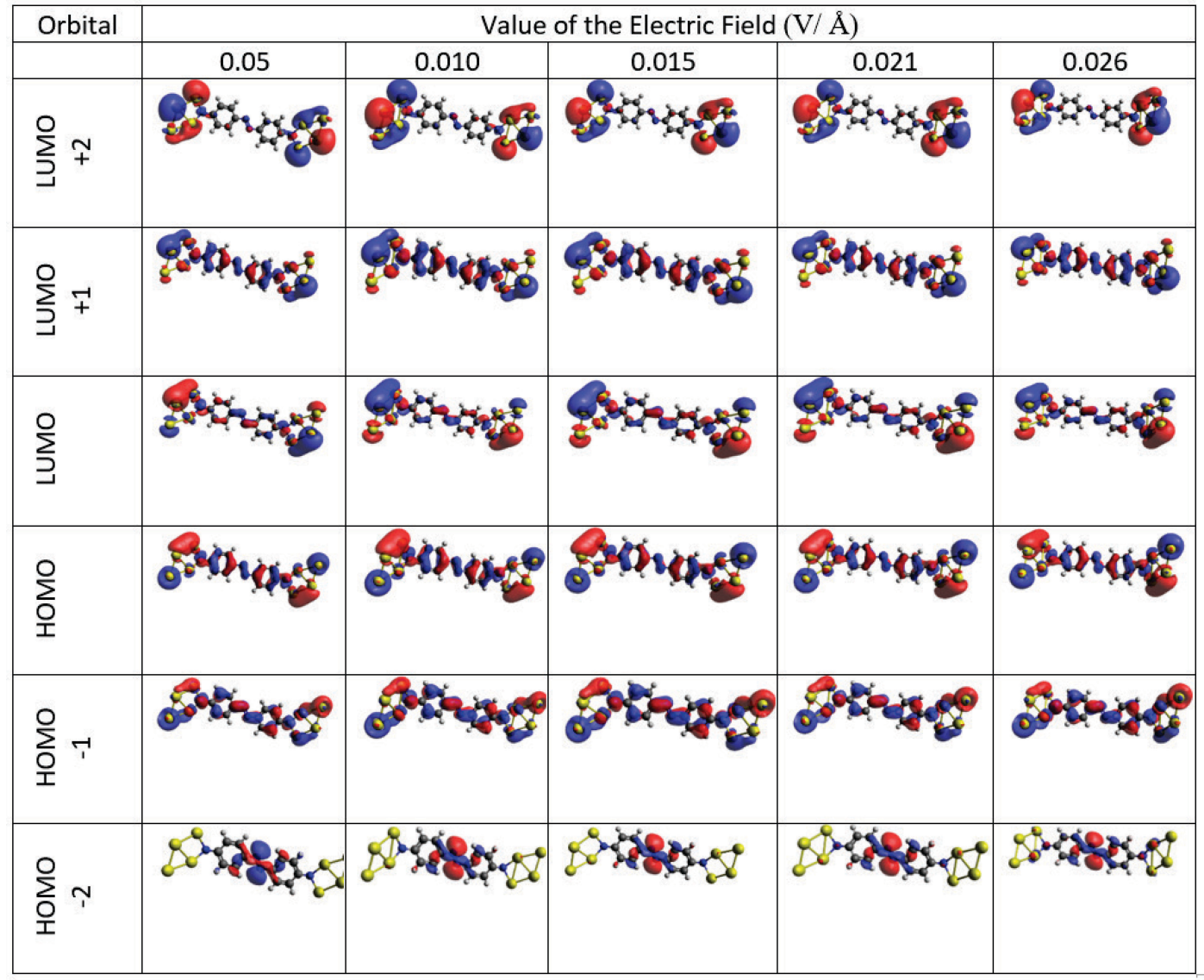

Figure 7. Isosurface representation of MOs of Extended Molecule II, considering four atoms in each binding site and different values of the applied electric field.

However, some reports in the literature indicate that the model works adequately well and it is able to reproducing the experimental values. ${ }^{[42]}$ In order to analyze the reliability of the EM-I and EM-II models reported in Figure 1. the number of gold atoms was increased to four to model the binding site on the gold surface. In Figure 7 we report the results obtained for EM-II, considering the new model of the electrode and under the influence of the different electric fields. Note that the spatial distribution of the MOs of the EM-II, under the influence of the different values of electric field, are similar to those when the gold electrode is represented by one atom. Similar results were obtained for EM-I. The above mentioned suggests that the model reported in Figure 1 is equivalent when the number of gold atoms in the binding site is increased.

\section{CONCLUSIONS}

In this work, it was analyzed the electrical properties of azobenzene when it is bonded to gold atoms through the linking agents ( $\mathrm{S}$ and $\mathrm{N}$-atoms), and under the influence of an electric field over the extended molecule. Structural analysis confirms the planarity of the molecular structure throughout the study. Under the influence of an EF, the HOMO and LUMO orbitals of EM-I shift symmetrically towards FL of bulk gold. But in EM-II, only HOMO is affected by the field indicating the significance of the hole transfer. All these analysis implies that the workability of azo-group of moltronic devices can be enhanced with nitrogen linking agent rather than the conventional sulfur linking agent.

Acknowledgment. The authors acknowledge the Science and Engineering Research Board, Department of Science and Technology (DST.SERB). Government of India for funding (EMR/2016/002892). LHMH gratefully acknowledges financial support from the Universidad Autónoma del Estado de Hidalgo. Guanajuato National Laboratory (CONACyT 123732) is acknowledged for supercomputing resources.

\section{REFERENCES}

[1] A. Aviram, M. A. Ratner. Chem. Phys. Lett. 1974, 29(2), 277-283.

https://doi.org/10.1016/0009-2614(74)85031-1 
[2] J. Jortner, M. A. Ratner et al. Molecular electronics. Blackwell Science Oxford; 1997.

[3] J. Chen, M. Reed, A. Rawlett et al. Science 1999, 286(5444), 1550-1552.

https://doi.org/10.1126/science.286.5444.1550

[4] L. E. Hall, J. R. Reimers, N. S. Hush et al. J. Chem. Phys. 2000, 112(3), 1510-1521.

https://doi.org/10.1063/1.480696

[5] J. Park, A.N. Pasupathy, J.I. Goldsmith. Nature. 2002, 417(6890), 722-725.

https://doi.org/10.1038/nature00791

[6] D. K. James, J. M. Tour. Molecular Wires and Electronics, Springer, 2005. pp. 33-62.

https://doi.org/10.1007/b136066

[7] F. Chen, J. Hihath, Z. Huang, et al. Annu. Rev. Phys. Chem. 2007, 58, 535-564. https://doi.org/10.1146/ annurev.physchem.58.032806.104523

[8] D. Xiang, X. Wang, C. Jia, et al. Chem. Rev. 2016, 116(7), 4318-4440. https://doi.org/10.1021/acs.chemrev.5b00680

[9] M .A. Reed, C. Zhou, C. J Muller et al. Science 1997, 278(5336), 252-254.

https://doi.org/10.1126/science.278.5336.252

[10] H. Basch, M.A. Ratner. J. Chem. Phys. 2003, 119(22), 11926-11942. https://doi.org/10.1063/1.1613941

[11] M. Samanta, W. Tian, S. Datta et al. Phys. Rev. B. 1996, 53(12), R7626-R7629. https://doi.org/10.1103/PhysRevB.53.R7626

[12] N. Robertson, C. A. McGowan, Chem. Soc. Rev. 2003, 32(2), 96-103. https://doi.org/10.1039/b206919a

[13] R. Magyar, S. Tretiak, Y. Gao, et al. Chem. Phys. Lett. 2005, 401(1), 149-156.

https://doi.org/10.1016/j.cplett.2004.10.155

[14] A. Esme, S. G. Sagdinc, J. Mol. Struct. 2013, 1048, 185195. https://doi.org/10.1016/j.molstruc.2013.05.022

[15] F. Karipcin, B. Dede, S. Percin-Ozkorucuklu, et al. Dyes Pigments 2010, 84(1), 14-18. https://doi.org/10.1016/j.dyepig.2009.06.010

[16] S. Wu, W. Qian, Z. Xia, et al. Chem. Phys. Lett. 2000, 330(5), 535-540.

https://doi.org/10.1016/S0009-2614(00)01135-0

[17] A. Mohajeri, A. Zare. Comput. Mater. Sci. 2009, 45, 935-940.

https://doi.org/10.1016/j.commatsci.2008.12.017

[18] Y. Komoto, S. Fujii, H. Nakamura, et al. Sci. Rep-UK, 2016, 6, 26606. https://doi.org/10.1038/srep26606

[19] T. Koyadeen, A. Kumar. Dig. J. Nanomater. Bios. 2020, 15, 447-458.

[20] S. Osella, P. Samorì, Jrm. Cornil. J. Phys. Chem. C. 2014, 118(32), 18721-18729.

https://doi.org/10.1021/jp504582a

[21] H. S. Nalwa. Handbook of Surfaces and Interfaces of Materials: Solid thin films and layers. Academic Press, 2001.

https://doi.org/10.1016/B978-012513910-6/50003-7
[22] P. Politzer, J. M. Seminario, Modern density functional theory: a tool for chemistry. Vol. 2. Elsevier, 1995. https://doi.org/10.1016/S1380-7323(05)80031-7

[23] W. Kohn, A. D. Becke, R. G. Parr, J. Phys. Chem. 1996, 100(31), 12974-12980.

https://doi.org/10.1021/jp960669|

[24] M. Frisch, G. Trucks, H. Schlegel et al. Gaussian 09, Revision A. 02; Gaussian, Inc: Wallingford, CT, 2009.

[25] P. J. Hay, W. R. Wadt, J. Chem. Phys. 1985, 82(1), 299-310. https://doi.org/10.1063/1.448975

[26] P. J. Hay, W. R. Wadt, J. Chem. Phys. 1985, 82(1), 270-283. https://doi.org/10.1063/1.448799

[27] T. V. Russo, R. L. Martin, P. J. Hay, J. Phys. Chem. 1995, 99(47), 17085-14087. https://doi.org/10.1021/j100047a007

[28] M. Di Ventra, S. Pantelides, N. Lang. Phys. Rev. Lett. 2000, 84(5), 979-982.

https://doi.org/10.1103/PhysRevLett.84.979

[29] E. Glendening, A. Reed, J. Carpenter et al. NBO, version 3.1. Gaussian Inc., Pittsburgh.

[30] T. Keith, J. Millam, K. Eppinnett et al. Gauss View 05, Dennington II. Inc, Shawnee Mission, KS. 2005.

[31] N. M. O'Boyle, A. L. Tenderholt, K. M. Langner. J. Comp. Chem. 2008, 29, 839-845.

https://doi.org/10.1002/jcc.20823

[32] M. Berkowitz, R.G. Parr, J. Chem. Phys. 1988, 88(4), 2554-2557. https://doi.org/10.1063/1.454034

[33] D. Nozaki, G. Cuniberti, Nano Research. 2009, 2(8), 648-659. https://doi.org/10.1007/s12274-009-9067-y

[34] C. Cojocaru, A. Airinei, N. Fifere. Springer Plus. 2013, 2(1), 586.

https://doi.org/10.1186/2193-1801-2-586

[35] H. Raissi, M. Yoosefian, S. Khoshkhou. Comput. Theor. Chem. 2012, 983, 1-6.

https://doi.org/10.1016/j.comptc.2011.12.002

[36] W. Sokalski, R. Gora, W. Bartkowiak et al. J. Chem. Phys. 2001, 114(13), 5504-5508.

https://doi.org/10.1063/1.1353586

[37] D. F. Perepichka, M. R. Bryce, Angew. Chem. Int. Ed. 2005, 44(34), 5370-5373.

https://doi.org/10.1002/anie.200500413

[38] W. M. Haynes, CRC handbook of chemistry and physics, CRC press, 2014.

[39] F. Weinhold, C. Landis, E. Glendening, Int. Rev. Phys. Chem. 2016, 35(3), 399-440.

https://doi.org/10.1080/0144235X.2016.1192262

[40] P. Politzer, D. G. Truhlar, Chemical Applications of Atomic and Molecular Electrostatic Potentials Springer Science \& Business Media, 2013.

[41] M. Torrent-Sucarrat, F. De Proft, P. W. Ayers, P. Geerlings, Phys. Chem. Chem. Phys. 2010, 12, 10721080. https://doi.org/10.1039/B919471A

[42] K. Selvaraju, M. Jothi, P. Kumaradhas, Comput Theor. Chem. 2012, 996, 1-10.

https://doi.org/10.1016/j.comptc.2012.06.025 